\title{
Sea Turtle Foraging Algorithm for Continuous Optimization Problems
}

\author{
Daranat Tansui ${ }^{+}$and Arit Thammano \\ Computational Intelligence Laboratory, Faculty of Information Technology, King Mongkut's Institute of \\ Technology Ladkrabang, Bangkok, 10520 Thailand
}

\begin{abstract}
For several modern algorithms - such as Genetic Algorithm (GA), Bee Colony Foraging Algorithm (BCFA), Ant Colony Optimization (ACO), and Particle Swarm Optimization (PSO) - their evolving searching and learning processes to obtain the best answer in a reasonable time imitate the behaviors of animals in nature. This article presents a new algorithm called Sea Turtle Foraging Algorithm (STFA) that imitates sea turtles' food searching behavior of tracking the odor trail of Dimethyl Sulfide (DMS) originated from food sources. The displacement of a turtle is dictated by its active swimming movement and its passive movement due to ocean current. Our proposed STFA was performance tested with 5 standard test functions, and it was found that STFA was very effective and efficient.
\end{abstract}

Keywords: sea turtle foraging, nature inspired algorithm, continuous optimization problems.

\section{Introduction}

Optimization is a process of getting the best possible result for a given condition or constraint. There is no universal method for solving all optimization problems in an equally efficient way. One way for a numerical algorithm to solve an optimization problem is to enumerate all possible solutions, but most problems are so complex that this exact method is virtually impractical. Evolutional computation is a way to solve complex optimization problems in reasonable time. Many popular evolutional algorithms are based on foraging behaviors of animals in nature such as ants, bees, birds and bacteria. Sea turtles are long-life and forever migrating throughout their life. They made us interested in constructing an algorithm that imitates their migrating and foraging behaviors. In this paper, we propose an optimization algorithm that was modeled after the foraging behavior of sea turtles that move toward food sources by following the sources' odor trail of dimethyl sulfide that fades with distance and time. The positions of turtles depend on an ocean current velocity and their own velocity [1] which is updated according to their fitness value that is the output of a specified objective function. The optimum solution is represented by the position of the turtle that possesses the highest fitness value at the end of a run. This algorithm was performance tested with 5 standard benchmark functions.

The rest of the paper is organized as follows: Section 2 describes our inspiration and the biological foundation; Section 3 is a detailed explanation of the proposed algorithm; Section 4 describes the benchmark functions used and discusses the experimental results; and Section 5 concludes this paper.

\section{Inspiration}

The proposed algorithm is inspired by the foraging behavior of a sea turtle. This section, therefore, gives some detail about the life of a sea turtle. There are seven species of sea turtles in two families. Six species are in Cheloniidae family, but leatherback is in Dermochelyidae family [2]. Sea turtles are skilled ocean

\footnotetext{
${ }^{+}$Corresponding author. Tel.: +6681-312-1317
}

E-mail address: 56606010@kmitl.ac.th. 
navigators. They travel thousands of kilometres during their lifetime, feeding and nesting [3]. They normally travel in an open sea where the current affects their movement. They also normally move in a linear manner, from one point to the next [4]. Sea turtles may drift passively with ocean current or swim actively to a destination.

During their long-distance migration, sea turtles feed on jellyfish and other invertebrates that are abundant in frontal areas of the ocean that have phytoplankton in high concentration. When it is fed upon, phytoplankton releases a substance called dimethylsulfoniopropionate (DMSP) which disintegrates into the dimethyl sulfide (DMS), an odorous substance. Because DMS is volatile, it is accumulated in the air above an oceanic area that has an abundance of phytoplankton. In principle then, DMS can serve as an indicator for high density of preys that turtles feed on. In actuality, sea turtles can detect DMS, so they are able to use this sensing ability to find favorable foraging areas $[5,6]$.

\section{Sea Turtle Foraging Algorithm}

In this section, we describe our Sea Turtle Foraging Algorithm (STFA). This algorithm is modeled after the food searching process of sea turtles. They sense the odor of dimethyl sulfide (DMS) emanated from their food sources and move toward the food source that gives out the strongest odor. Their movement is also assisted by ocean current. The proposed algorithm which is inspired by the above foraging process is described in the following steps:

Step 1: Specify an initial population of $\mathrm{N}$ turtles, and randomly generate the initial position of each turtle.

$$
\mathrm{P}_{\mathrm{i}}(0)=\left[\mathrm{p}_{1}^{\mathrm{i}}, \mathrm{p}_{2}^{\mathrm{i}}, \ldots, \mathrm{p}_{\mathrm{D}}^{\mathrm{i}}\right]
$$

where $\mathrm{i}=1$ to $\mathrm{N}$, within a D-dimensional continuous search space.

Step 2: Randomly generate the initial velocities of sea turtles, $V_{i}(0)=\left[v_{1}^{i}, v_{2}^{i}, \ldots, v_{D}^{i}\right]$. The velocity of the turtle is constrained to be within the limits represented by equations (2) and (3).

$$
\begin{gathered}
\mathrm{V}_{\max }=\alpha(\mathrm{XUB}-\mathrm{XLB}) \\
\mathrm{V}_{\min }=-\mathrm{V}_{\max }
\end{gathered}
$$

where XUB and XLB are the upper and lower bounds of the D-dimensional search space, and $\alpha$ is a constant in the range $[0,1]$.

Step 3: Randomly generate the initial positions of $\mathrm{M}$ food sources.

$$
\mathrm{K}_{\mathrm{j}}(0)=\left[\mathrm{k}_{1}^{\mathrm{j}}, \mathrm{k}_{2}^{\mathrm{j}}, \ldots, \mathrm{k}_{\mathrm{D}}^{\mathrm{j}}\right]
$$

where $\mathrm{j}=1$ to $\mathrm{M}$, within a D-dimensional continuous search space.

Step 4: Input the initial position of each food source into the objective function and evaluate it to obtain the fitness value of that food source.

Step 5: Input the position of each turtle into an objective function and evaluate it to obtain the fitness value of that turtle; the one with the highest fitness value, I, is recorded.

$$
\mathrm{I}=\underset{\mathrm{i}}{\arg \max }\left(\mathrm{f}_{\mathrm{P}_{\mathrm{i}}(\mathrm{t})}\right)
$$

where $f_{P_{i}(t)}$ is the fitness value of the turtle $i$ at time $t$.

Step 6: Update the velocity of each sea turtle as follows:

$$
V_{i}(t)=V_{i}(t-1)+\left(\frac{f_{P_{i}(t)}-f_{P_{i}(t-1)}}{f_{P_{i}(t-1)}}\right)\left(P_{i}(t)-P_{i}(t-1)\right)
$$


where $\mathrm{P}_{\mathrm{i}}(\mathrm{t})$ is the position of the turtle at time $\mathrm{t}$ and $\mathrm{P}_{\mathrm{i}}(\mathrm{t}-1)$ is its position at time $\mathrm{t}-1$.

Step 7: Calculate the velocities of the ocean currents, $\mathrm{VC}_{\mathrm{i}}(\mathrm{t})=\left[\mathrm{vc}_{1}^{\mathrm{i}}, \mathrm{vc}_{2}^{\mathrm{i}}, \ldots, \mathrm{vc}_{\mathrm{D}}^{\mathrm{i}}\right]$.

$$
\mathrm{VC}_{\mathrm{i}}(\mathrm{t})=\alpha\left(\mathrm{P}_{\mathrm{I}}(\mathrm{t})-\mathrm{P}_{\mathrm{i}}(\mathrm{t})\right)
$$

Step 8: Add the velocity of the turtle to that of the ocean current to get the combined velocity.

$$
\mathrm{VM}_{\mathrm{i}}(\mathrm{t})=\mathrm{V}_{\mathrm{i}}(\mathrm{t})+\mathrm{VC}_{\mathrm{i}}(\mathrm{t})
$$

Step 9: Compare the fitness value of each turtle with the fitness value of each food source. If the fitness value of the turtle is higher than that of the food source, then the contribution of that food source is taken to be zero. However, if the fitness value of the turtle is lower than that of the food source, then the contribution of that food source is set to be the following term:

$$
\mathrm{CK}_{\mathrm{j}}=\mathrm{f}_{\mathrm{K}_{\mathrm{j}}} / \sum_{\mathrm{q}=1}^{\mathrm{M}} \mathrm{f}_{\mathrm{K}_{\mathrm{q}}}
$$

where $f_{K_{j}}$ is the fitness value of the food source $j$.

Step 10: Calculate the distance between the turtle and the food source.

$$
\mathrm{d}_{\mathrm{ij}}=\left\|\mathrm{P}_{\mathrm{i}}-\mathrm{K}_{\mathrm{j}}\right\|
$$

Step 11: Calculate the level of DMS odor from the food source $\mathrm{j}$ perceived by the turtle $\mathrm{i}, \mathrm{C}_{\mathrm{ij}}(\mathrm{t})$. The level of DMS odor influences the movement of the turtle to its next position.

$$
\begin{gathered}
\mathrm{C}_{\mathrm{ij}}(\mathrm{t})=\left(\mathrm{CK}_{\mathrm{j}} \times \exp \left(-\mathrm{d}_{\mathrm{ij}}^{2} / 2 \sigma^{2}(\mathrm{t})\right)\right) \\
\sigma(\mathrm{t})=\sigma_{0} \exp (-\mathrm{t} / \mathrm{T})
\end{gathered}
$$

where $\sigma(t)$ signifies the fading of the level of DMS odor with passing time, $\sigma_{0}$ is a constant set to be equal to 1 , and $\mathrm{T}$ is the number of iterations representing the longest time after which the odor completely disappears.

Step 12: Determine the best food source for the turtle i. The best food source is the one that has the highest value of $\mathrm{C}_{\mathrm{ij}}(\mathrm{t})$ among all of the food sources.

$$
\mathbf{J}=\underset{\mathrm{j}}{\arg \max }\left(\mathrm{C}_{\mathrm{ij}}\right)
$$

Step 13: Update the position of each turtle according to equation (14).

$$
\mathrm{P}_{\mathrm{i}}(\mathrm{t}+1)=\mathrm{P}_{\mathrm{i}}(\mathrm{t})+\eta \mathrm{VM}_{\mathrm{i}}(\mathrm{t})+\mathrm{C}_{\mathrm{iJ}}(\mathrm{t})\left(\mathrm{K}_{\mathrm{J}}-\mathrm{P}_{\mathrm{i}}\right)
$$

Step 14: Check the stopping criterion. If the maximum number of iterations is reached, the algorithm will be terminated. If not, the following two conditions are checked: $i)$ if the value of $t / T$ is an integer number, go back to step 3; ii) if the value of $t / T$ is not an integer number, go back to step 5 .

\section{Results and Discussion}

In this preliminary stage, the performance of the proposed model was tested with five standard benchmark functions as shown in Table 1. The first two functions are maximization functions while the rest are minimization functions. 
Table 1. Benchmark functions

\begin{tabular}{|l|l|l|}
\hline \multicolumn{1}{|c|}{ Functions } & \multicolumn{1}{|c|}{ Domains } & $\mathrm{f}_{\text {optimum }}$ \\
\hline $\mathrm{f}(\overrightarrow{\mathrm{x}})=-\left(\mathrm{x}_{1}^{2}+\mathrm{x}_{2}^{2}\right)+4$ & $\mathrm{x}_{1}, \mathrm{x}_{2} \in[-10,10]$ & 4 \\
\hline $\mathrm{f}(\overrightarrow{\mathrm{x}})=21.5+\mathrm{x}_{1} \sin \left(4 \pi \mathrm{x}_{1}\right)+\mathrm{x}_{2} \sin \left(20 \pi \mathrm{x}_{2}\right)$ & $\mathrm{x}_{1} \in[-3.0,12.1], \mathrm{x}_{2} \in[4.1,5.8]$ & 38.850294479 \\
\hline $\mathrm{f}(\overrightarrow{\mathrm{x}})=\sum_{\mathrm{i}=1}^{\mathrm{D}}\left|\mathrm{x}_{\mathrm{i}}\right|^{(\mathrm{i}+1)}$ & $\mathrm{x}_{\mathrm{i}} \in[-1,1]$ & 0 \\
\hline $\mathrm{f}(\overrightarrow{\mathrm{x}})=\left(1.5-\mathrm{x}_{1}+\mathrm{x}_{1} \mathrm{x}_{2}\right)^{2}+\left(2.25-\mathrm{x}_{1}+\mathrm{x}_{1} \mathrm{x}_{2}^{2}\right)^{2}+\left(2.625-\mathrm{x}_{1}+\mathrm{x}_{1} \mathrm{x}_{2}^{3}\right)^{2}$ & $\mathrm{x}_{1}, \mathrm{x}_{2} \in[-4.5,4.5]$ & 0 \\
\hline $\mathrm{f}(\overrightarrow{\mathrm{x}})=\sum_{\mathrm{i}=0}^{\mathrm{D}-1} \mathrm{ix}_{\mathrm{i}}^{4}$ & $\mathrm{x}_{\mathrm{i}} \in[-10,10]$ & 0 \\
\hline
\end{tabular}

The experimental results show that the proposed STFA can achieve optimal solutions in 4 out of 5 benchmark functions. STFA fails to locate the global optimum of the second function; the best result found by STFA is 38.635704. Moreover, to get good results, the most difficult part is to properly determine the value of $\mathrm{T}$, which controls the time the odor completely disappears. Future research will focus on this issue.

\section{Conclusion}

This paper proposes a new nature inspired algorithm for continuous optimization problems based on the foraging behavior of a sea turtle. The performances of the proposed STFA algorithm were examined with five benchmark functions. The experimental results showed that the proposed algorithm performed very well on these functions. Our future work will be on increasing the efficiency of the proposed algorithm by allowing the algorithm to automatically determine the system parameters and applying it to more complicated problems.

\section{References}

[1] M. Abecassis, I. Senina, P. Lehodey, P. Gaspar, D. Parker, G. Balazs, J. Polovina. A model of loggerhead sea turtle (Caretta caretta) habitat and movement in the oceanic north pacific. PLoS ONE, 8(9): e73274, doi:10.1371/journal.pone.0073274

[2] Wikipedia. Sea turtle. https://en.wikipedia.org/wiki/Sea_turtle

[3] F. Bentivegna, F. Valentino, P. Falco, E. Zambianchi, S. Hochscheid. The relationship between loggerhead turtle (Caretta caretta) movement patterns and Mediteranean currents. Marine Biology. 2007, 151: 1605-1614.

[4] J. Okuyama, O. Abe, H. Nishizawa, M. Kobayashi, K. Yoseda, N. Arai. Ontogeny of the dispersal migration of green turtle (Chelonia mydas) hatchlings. Journal of Experimental Marine Biology and Ecology. 2009, 379: 43-50.

[5] G. A. Nevitt. Sensory ecology on the high seas: the odor world of the procellariiform seabirds. The Journal of Experimental Biology. 2008, 211: 1706-1713.

[6] C. S. Endres and K. J. Lohmann. Perception of dimethyl sulfide (DMS) by loggerhead sea turtles: a possible mechanism for locating high-productivity oceanic regions for foraging. The Journal of Experimental Biology. 2012, 215: 3535-3538. 